\title{
Localized gingival enlargements. A clinicopathological study of 1187 cases
}

\author{
Paris Tamiolakis ${ }^{1}$, Eirini Chatzopoulou ${ }^{2}$, Fiorina Frakouli ${ }^{3}$, Konstantinos I. Tosios ${ }^{4}$, Alexandra Skla- \\ vounou-Andrikopoulou ${ }^{5}$
}

${ }^{1}$ DDS, Postgraduate Student, Department of Oral Medicine and Pathology, School of Dentistry, National and Kapodistrian University of Athens, Greece

${ }^{2}$ DDS, Msc in Oral Biology, School of Dentistry, National and Kapodistrian University of Athens, Greece

${ }^{3}$ DDS, School of Dentistry, National and Kapodistrian University of Athens, Greece

${ }^{4}$ DDS, PhD, Assistant Professor, Department of Oral Medicine and Pathology, School of Dentistry, National and Kapodistrian University of Athens, Greece

${ }^{5}$ DDS, MSc, PhD, Professor, Head of Department of Oral Medicine and Pathology, School of Dentistry, National and Kapodistrian University of Athens, Greece

Correspondence:

41 Amyclon Str, 11142

Lamprini, Athens, Greece

ptamiolakis@hotmail.com

Received: $31 / 10 / 2017$

Accepted: 10/04/2018

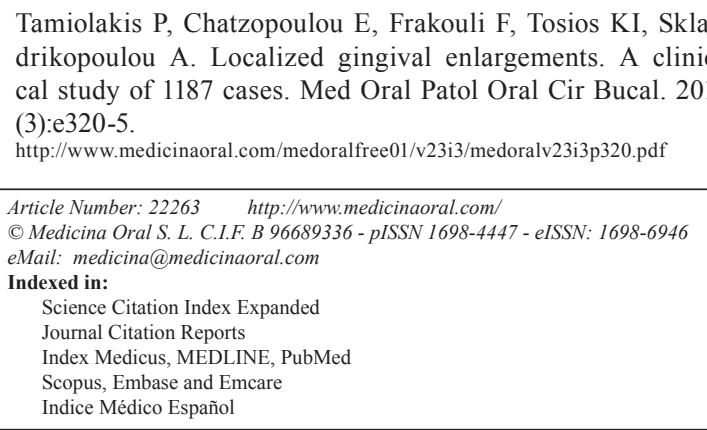

\begin{abstract}
Background: To describe the incidence, demographic and clinical features of 1187 localized gingival enlargements.

Material and Methods: 1187 cases of localized gingival enlargements diagnosed during a 20-year period were retrospectively collected. The patients' gender and age, as well as the main clinical features of the tumors were retrieved from the biopsy report forms.

Results: The 1187 localized gingival enlargements represented $6.23 \%$ of 19.044 biopsies performed during the study period. 756 females and 427 males were affected with a mean age of $41.92 \pm 19.68$ years. The lesions appeared as smooth $(52.4 \%)$, granular $(17.9 \%)$ or rough $(13.16 \%)$ tumors, elastic $(50.73 \%)$ or soft $(29.56 \%)$ in consistency and red $(60.8 \%)$, normal $(28.58 \%)$ or white $(8.17 \%)$ in color. The majority of the lesions $(85.17 \%)$ were reactive in origin with pyogenic granuloma being the most common. In $1.1 \%$ of the cases a diagnosis of malignant lesion was rendered.

Conclusions: All localized gingival enlargements should be submitted for microscopic examination because in approximately $1 \%$ of cases they are malignant.
\end{abstract}

Key words: Localized gingival enlargements, gingival mass, gingival lesions, gingival reactive lesions, gingival malignant lesions. 


\section{Introduction}

Localized gingival enlargements (LGEs) are common in clinical practice $(1,2)$ and are usually of reactive origin $(1,2)$ developing as a response to chronic local irritation or trauma (3). Most published studies focus on reactive LGEs (3-6) i.e. fibrous hyperplasia (FH), pyogenic granuloma (PG), peripheral ossifying fibroma (POF) and peripheral giant cell granuloma (PGCG). However, benign and malignant neoplasms (2), lesions of dysplastic origin (7) and lesions representing manifestations of systemic diseases (2) may also occur. Truschnegg et al. (8) and Bernick (9) studied 92 and 864 cases of LGEs, respectively. However, in the first study the number of cases was too small for valid conclusions to be made, while in the later LGEs were studied together with localized enlargements of the palate.

The aim of the present study is to report the incidence, demographic and clinical features of 1187 LGEs.

\section{Material and Methods}

In this retrospective study all Biopsy Request Forms accompanying biopsies submitted to our Laboratory from 1995 to 2015 were searched using the keywords "tumor" and "gingiva" in the predefined list of clinical terms. For each case the patient's gender and age, location and clinical features of the lesions were tabulated. Final diagnosis was retrieved from the Pathology report. Cases reported as localized on the "alveolar mucosa" or "edentulous alveolar ridge" were excluded from the study.

\section{Results}

A total of 1187 cases of LGEs affecting 1187 patients represented $6.23 \%$ of 19.044 biopsies accessioned during the study period. Diagnoses are tabulated in Table 1. Most lesions $(85.17 \%)$ were reactive in origin, with PG being the most common (27.8\%), followed by POF (27.38\%), FH (13.73\%), PGCG (12.38\%) and fibroepithelial hyperplasia (FEH) (3.88\%). Other common lesions in descending order were papilloma $(2.27 \%)$, gingival inflammation $(2.11 \%)$ giant cell fibroma (1.94\%) and peripheral odontogenic tumors $(1.43 \%)$. Malignant lesions were rare (1.1\%).

In Figures 1 and 2 gender and age distribution for all LGEs as well as for particular entities diagnosed in at least 10 patients are tabulated. As a whole, LGEs showed a female predominance, with 756 cases $(63.91 \%)$ occurring in female patients compared to 427 (36.09\%) in males (male to female ratio 0.56:1). Most patients were in the 4 th -6 th decade of life, with a mean age of $41.92 \pm 19.68$ years (median age 43 years). The difference between the mean age of males $(41.12 \pm 21.2$ years, median age 42 years) and females ( $42.4 \pm 18.76$ years, median age 43 years) was not statistical significant. Giant cell fibroma and papilloma occurred in younger patients and malignant lesions in older patients, compared to

Table 1: Diagnosis of localized gingival enlargements.

\begin{tabular}{|c|c|}
\hline Diagnosis (number of lesions) & $\%$ \\
\hline Pyogenic granuloma (330) & 27.8 \\
\hline Peripheral ossifying fibroma (325) & 27.38 \\
\hline Fibrous hyperplasia (163) & 13.73 \\
\hline Peripheral giant cell granuloma (147) & 12.38 \\
\hline Fibroepithelial hyperplasia (46) & 3.88 \\
\hline Papilloma (27) & 2.27 \\
\hline Gingival inflammation (25) & 2.11 \\
\hline Giant cell fibroma (23) & 1.94 \\
\hline $\begin{array}{l}\text { Peripheral odontogenic tumors (17): Peripheral odontogenic fibroma (12); Peripheral ameloblastoma (2); } \\
\text { Peripheral dentinogenic ghost cell tumor (2); Peripheral odontogenic myxoma (1) }\end{array}$ & 1.43 \\
\hline $\begin{array}{l}\text { Malignant lesions (13): Squamous cell carcinoma (6); Lymphoma (2); Extramedullary plasmatocytoma (2); } \\
\text { Metastatic breast carcinoma (1); Metastatic lung carcinoma (1); Metastatic prostate carcinoma (1) }\end{array}$ & 1.1 \\
\hline $\begin{array}{l}\text { Other (71): Fistula granuloma (10); Hemangioma (8); Epithelial hyperplasia (5) Wart (5); Localized } \\
\text { juvenile spongiotic gingival hyperplasia (4); Granulation tissue (4); Peripheral nerve sheath tumor (3); } \\
\text { Abscess (3); Benign papillary lesion (3); Plasma cell granuloma (2); Benign fibrous histiocytoma (2); } \\
\text { Fibromyxoma (2); Condyloma acuminatum (2); Intramucosal nevus (1); Exostosis (1); Mild epithelial } \\
\text { dysplasia (1); Focal mucinosis (1); Verruciform xanthoma (1); Thrombus (1); Fibrolipoma (1); Intraoral } \\
\text { sebaceous hyperplasia (1); Brown tumor (1); Lysosomal storage disease (1); Epithelioid cell histiocytoma } \\
\text { (1); Benign fibrous proliferation (1); Lipoma (1); Myxoid calcified hamartoma (1); Myofibroma (1); Bone } \\
\text { hamartoma (1); Bone choristoma (1); Gingival cyst of adult (1) }\end{array}$ & 5.98 \\
\hline
\end{tabular}




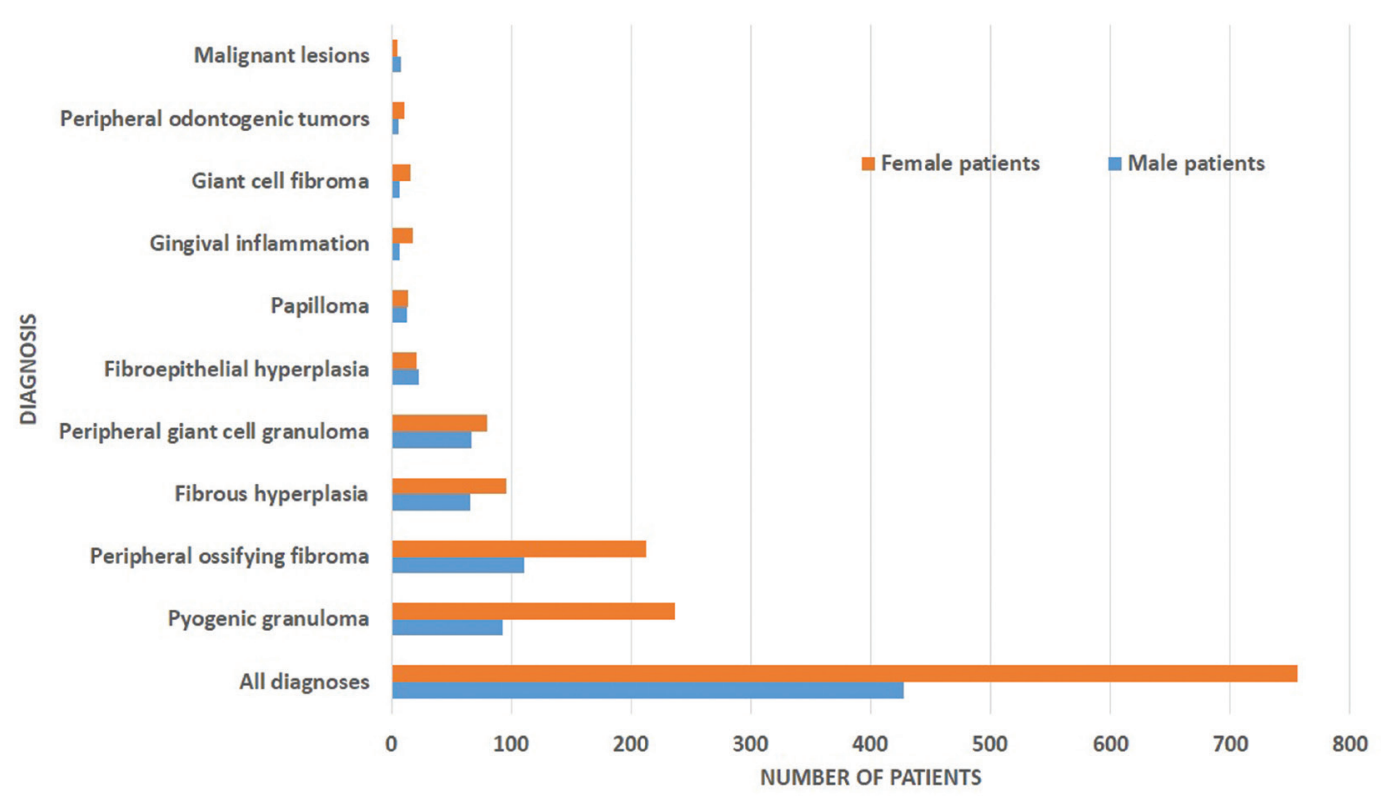

Fig. 1: Gender of patients (for lesions occurring at least in 10 patients).

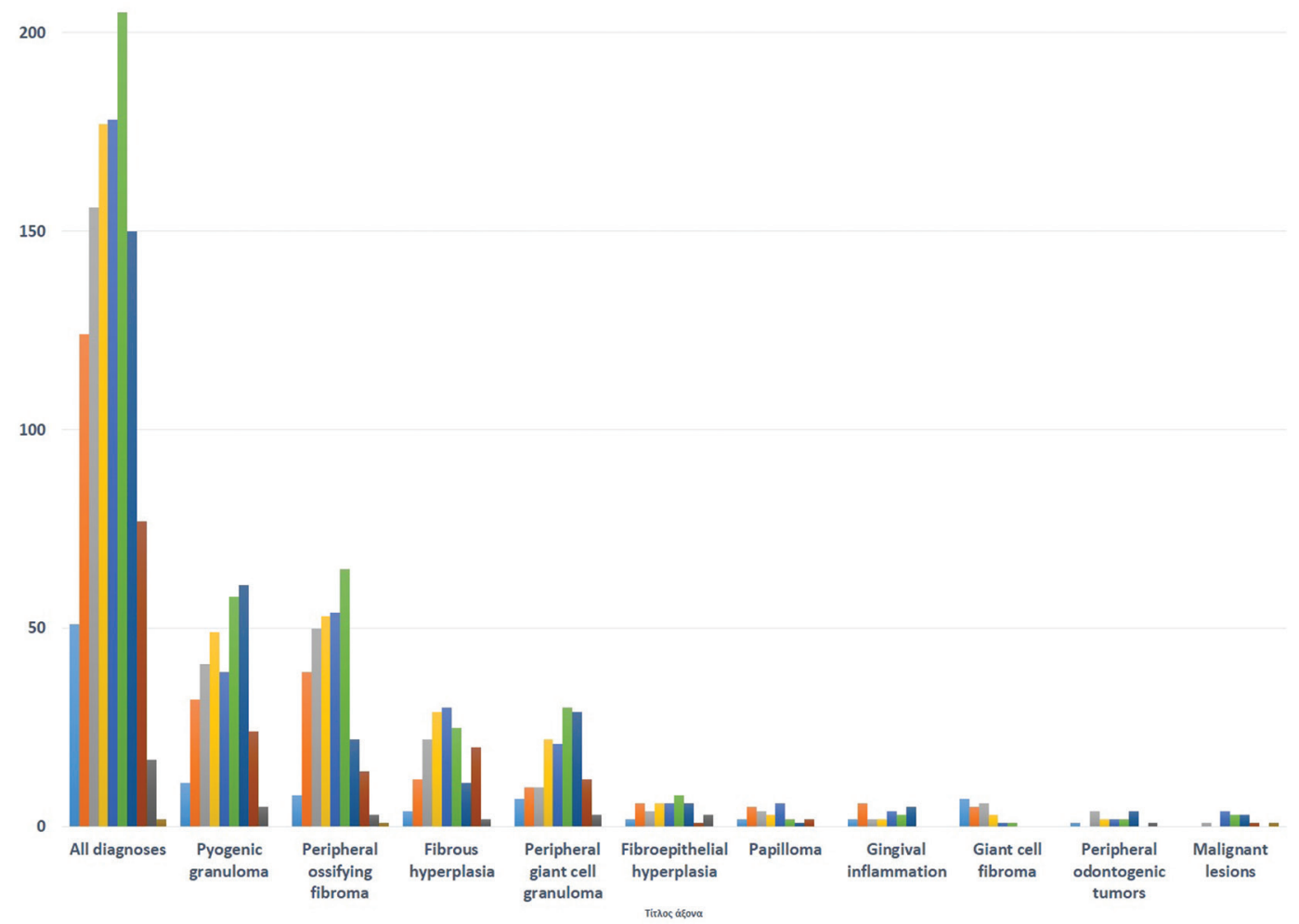

Fig. 2: Age of patients related to decade of life (for lesions occurring at least in 10 patients).

Ist decade (0-9 years) ind decade (10-19 years) $\approx 3$ rd decade $(20-29$ years $)$ ath decade $(30-39$ years $)$ - 5 th decade ( $40-49$ years) $\square$ th decade ( $50-59$ years) - 7 th decade $(60-69$ years) - 8 th decade ( $70-79$ years) - 9 th decade $(80-89$ years) - 10 th decade $(90-99$ years 
LGEs. LGEs showed a slight predilection for the maxilla $(51.73 \%)$, compared to the mandible (48.28\%), as well as for anterior areas $(58.49 \%)$, compared to posterior ones (41.51\%). They were more common in the anterior maxilla (33.02\%), followed by the anterior mandible $(25.48 \%)$, posterior mandible $(22.79 \%)$ and posterior maxilla (18.7\%). FEH, papilloma and malignant lesions occurred more frequently in the posterior part of the mandible (Fig. 3). of cases) and FEH (17.5\% of cases) were more possible to have a papillary surface, while malignant lesions ( $25 \%$ of cases) and giant cell fibromas ( $23.81 \%$ of cases) to have a rough one. LGEs measured approximately $1.15 \pm 0.8 \mathrm{~cm}$ (median size $1 \mathrm{~cm}$ ) in the largest diameter. Malignant lesions had the largest mean size among LGEs $(1.98 \pm 0.84 \mathrm{~cm}$.), while papillomas $(0.58 \pm 0.31 \mathrm{~cm})$ and giant cell fibromas $(0.63 \pm 0.35 \mathrm{~cm})$ the lowest. LGEs were asymptomatic in $82.39 \%$ of cases justifying the

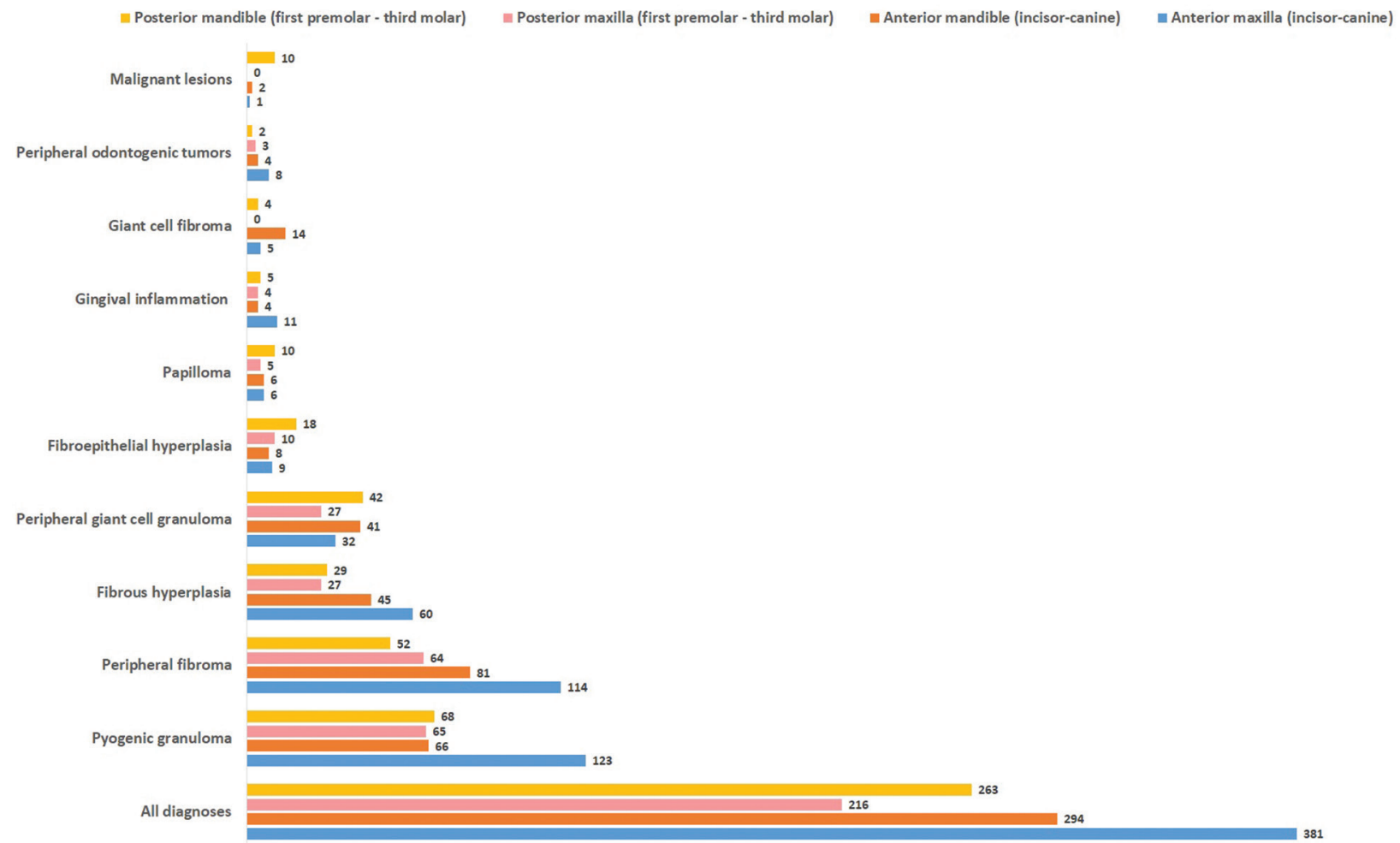

Fig. 3: Site of localized gingival enlargements (for lesions occurring at least in 10 patients).

Clinically LGEs were described as sessile $(50.9 \%)$ or pediculated masses $(49.1 \%)$; of red $(60.8 \%)$, normal $(28.58 \%)$ or white $(8.17 \%)$ color; elastic $(50.73 \%)$ or soft (29.56\%) in consistency; and with smooth (52.4\%), granular $(17.9 \%)$ or rough $(13.16 \%)$ surface. There were few significant divergences from the aforementioned clinical characteristics. Concerning pediculus, lesions that differed were gingival inflammation, peripheral odontogenic tumors and malignant lesions, the vast majority of which were sessile $(77.27 \%, 100 \%$ and $88.89 \%$ respectively). The majority of PG, PGCG, and gingival inflammation $(85.13 \%, 84.78 \%$ and $91.3 \%$ respectively) were red in color, whereas $37.5 \%$ of papillomas and $52.38 \%$ of giant cell fibromas were white. In contrast to all the other LGEs, papillomas (41.67\%) and malignant lesions $(25 \%)$ most commonly had a granular rather than smooth surface. Also papillomas $(29.17 \%$ long duration of $12.76 \pm 21.61$ months (median duration 5 months) before diagnosis. FH (20.33 \pm 32.84 months) and giant cell fibroma (33.53 \pm 39.48 months) had the longest mean duration before diagnosis, whereas malignant lesions (2.64 \pm 1.98 months) and gingival inflammation (6.12 \pm 9.23 months) had the shortest.

Recurrence was reported in POF (7 cases), PG (5 cases), PGCG (4 cases), FH (2 cases) papilloma and peripheral odontogenic fibroma (1 case each).

\section{Discussion}

In this retrospective study the incidence, demographic and clinical features of 1187 LGEs were described, while in previous studies only reactive LGEs were included (3-6). They represented $6.23 \%$ of all biopsies accessioned in the study period which is higher than the percentage of $4 \%$ seen in adults (10) and $2.3 \%$ in 
children up to 16 year-old (11) reported in other studies during a 30 -year period.

Most LGEs, PG, POF, FH and PGCG were of reactive origin, and represented $5.35 \%$ of all biopsies of the study period which is comparable to the frequency reported in previous studies, $6.7 \%$ (3), $6.4 \%$ (4), $5 \%$ (5) and 3.6\% (6) respectively. Although in the aforementioned studies FH was the most common reactive LGE, representing $31.8 \%$ (3), $61.2 \%$ (4), $45.5 \%$ (5), and $61 \%$ (6), in the present study PG was the most common (34.2\%), followed by POF (33.68\%) and FH (16.9\%). Differences in the relative frequency of reactive LGEs in various studies (3-6) have been attributed to heterogeneity of the study populations or to different histopathologic criteria (3). The clinical features of the four reactive LGEs are in accordance with previous reports (3). In 18 cases of reactive LGEs recurrence was recorded, but as the data of the present study were extracted from biopsy report forms, conclusions on recurrence rates cannot be drawn.

Peripheral odontogenic tumors represented $1.43 \%$ of all LGEs and $0.09 \%$ of all specimens submitted for histopathologic examination during the study period, while in previous studies these tumors represented $0.05 \%$ of all specimens submitted for histopathologic examination (13), and their relative frequency among all odontogenic tumors ranged from $0.1 \%$ to $8.9 \%$ (13). Peripheral odontogenic fibroma was the most common peripheral odontogenic tumor followed by peripheral ameloblastoma which is in accordance with previous studies (1315). Similarly, according to a previous report, peripheral odontogenic fibroma in our study, exhibited a female predominance, a predilection for middle aged patients, and for the anterior part of the maxilla and the mandible (16). Peripheral ameloblastoma represents $0-10 \%$ of all ameloblastomas (13), while the two cases of peripheral dentinogenic ghost cell tumors and the single case of peripheral odontogenic myxoma detected in our series are extremely unusual tumors, as only 50 cases (17) and 6 cases (18), respectively, have been included in recent reviews.

Squamous cell carcinoma was the most common malignant LGE in our study. It presented in four female and two male patients, with a mean age of 58.3 years. All lesions arose on the mandibular gingiva, five on the posterior and one on the anterior. Gingival squamous cell carcinoma accounts for less than $10 \%$ to as high as $30 \%$ of all oral squamous cell carcinomas and shows almost equal gender distribution and a predilection for older patients (19). It occurs most commonly on the posterior mandibular gingiva as an exophytic mass, usually ulcerated (19). It is noteworthy that many practitioners report reactive gingival lesions in the differential diagnosis of gingival squamous cell carcinoma (19), while in our study, a provisional diagnosis of reactive lesion was given in half of the cases of squamous cell carcinoma. Three cases of metastatic tumors, two cases of lymphoma and two cases of extramedullary plasmatocytomas presenting as LGE were also detected in our material. The gingiva is the most common soft tissue site of metastasis (20), and the 4th most common site of oral lymphoma development followed by the maxilla, palate and the mandible $(21,22)$. The lesions may mimic reactive lesions (20). Metastatic tumors are seen in the presence of widespread disease, and lung, breast and kidney carcinoma metastasize more often to the oral soft tissues compared to other tumors (20). In our material, the metastatic tumors originated from the breast, lung and prostate; they occurred in two male and one female patients with a mean age 64 years; two lesions presented in the posterior mandibular gingiva and the other in the anterior maxillary gingiva.

\section{Conclusions}

LGE are common in clinical practice and most are of reactive origin, but approximately $1 \%$ are malignant. Therefore, all LGEs should be submitted for microscopic examination and not diagnosed as benign based on the clinical impression and expertise.

\section{References}

1. Savage NW, Daly CG. Gingival enlargements and localized gingival overgrowths. Aust Dent J. 2010;55:55-60.

2. Agrawal AA. Gingival enlargements: Differential diagnosis and review of literature. World J Clin Cases. 2015;3:779-88.

3. Buchner A, Shnaiderman-Shapiro A, Vered M. Relative frequency of localized reactive hyperplastic lesions of the gingiva: a retrospective study of 1675 cases from Israel. J Oral Pathol Med. 2010;39:631-8. 4. Daley TD, Wysocki GP, Wysocki PD, Wysocki DM. The major epulides: clinicopathological correlations. J Can Dent Assoc. 1990;56:627-30.

5. Layfield LL, Shopper TP, Weir JC. A diagnostic survey of biopsied gingival lesions. J Dent Hyg. 1995;69:175-9.

6. Zhang W, Chen Y, An Z, Geng N, Bao D. Reactive gingival lesions: a retrospective study of 2,439 cases. Quintessence Int. 2007;38:10310.

7. Figueiredo LM, Trindade SC, Sarmento VA, Muniz WR, Valente RO. Extensive gingival hemangioma in a 10 -year-old boy treated by sclerotherapy: a case report. J Oral Maxillofac Surg. 2012;70:2585-9. 8. Truschnegg A, Acham S, Kiefer BA, Jakse N, Beham A. Epulis: a study of 92 cases with special emphasis on histopathological diagnosis and associated clinical data. Clin Oral Investig. 2016;20:1757-64. 9. Bernick S. Growths of the gingiva and palate; chronic inflammatory lesions. Oral Surg Oral Med Oral Pathol. 1948;1:1029-41.

10. Jones AV, Franklin CD. An analysis of oral and maxillofacial pathology found in adults over a 30-year period. J Oral Pathol Med. 2006;35:392-401.

11. Jones AV, Franklin CD. An analysis of oral and maxillofacial pathology found in children over a 30 -year period. Int J Paediatr Dent. 2006;16:19-30.

12. daSilva FC, Piazzetta CM, Torres-Pereira CC, Schussel JL, Amenábar JM. Gingival proliferative lesions in children and adolescents in Brazil: A 15-year-period cross-sectional study. J Indian Soc Periodontol. 2016;20:63-6.

13. Buchner A, Merrell PW, Carpenter WM. Relative frequency of peripheral odontogenic tumors: a study of 45 new cases and comparison with studies from the literature. J Oral Pathol Med. 2006;35:38591. 
14. Ide F, Obara K, Mishima K, Saito I, Horie N, Shimoyama T, Kusama K. Peripheral odontogenic tumor: a clinicopathologic study of 30 cases. General features and hamartomatous lesions. J Oral Pathol Med. 2005;34:552-7.

15. Ide F, Mishima K, Saito I, Kusama K. Rare peripheral odontogenic tumors: report of 5 cases and comprehensive review of the literature. Oral Surg Oral Med Oral Pathol Oral Radiol Endod. 2008;106:22-8

16. Ritwik P, Brannon RB. Peripheral odontogenic fibroma: a clinicopathologic study of 151 cases and review of the literature with special emphasis on recurrence. Oral Surg Oral Med Oral Pathol Oral Radiol Endod. 2010;110:357-63.

17. Chrcanovic BR, Gomez RS. Peripheral calcifying cystic odontogenic tumour and peripheral dentinogenic ghost cell tumour: an updated systematic review of 117 cases reported in the literature. Acta Odontol Scand. 2016;74:591-597.

18. Raubenheimer EJ, Noffke CE. Peripheral odontogenic myxoma: a review of the literature and report of two cases. J Maxillofac Oral Surg. 2012;11:101-4.

19. Fitzpatrick SG, Neuman AN, Cohen DM, Bhattacharyya I. The clinical and histologic presentation of gingival squamous cell carcinoma: a study of 519 cases. Oral Surg Oral Med Oral Pathol Oral Radiol. 2012;114:509-15.

20. Hirshberg A, Berger R, Allon I, Kaplan I. Metastatic tumors to the jaws and mouth. Head Neck Pathol. 2014;8:463-74.

21. Alli N, Meer S. Head and neck lymphomas: A 20-year review in an Oral Pathology Unit, Johannesburg, South Africa, a country with the highest global incidence of HIV/AIDS. Oral Oncol. 2017;67:1723.

22. Kemp S, Gallagher G, Kabani S, Noonan V, O'Hara C. Oral nonHodgkin's lymphoma: review of the literature and World Health Organization classification with reference to 40 cases. Oral Surg Oral Med Oral Pathol Oral Radiol Endod. 2008;105:194-201.

\section{Acknowledgements}

None.

\section{Conflict of interest}

The authors declares that he has no conflict of interest

The study was approved by the Research Ethics Committee of Athens Dental School (code number 348/30.10.2017). 